\title{
Triiodothyronine Enhances Renal Response to Aldosterone in the Rabbit Collecting Tubule
}

\author{
C. Barlet and A. Doucet \\ Laboratoire de Physiologie Cellulaire, Collège de France, 75231 Paris Cedex 05, France
}

\begin{abstract}
Since thyroid hormones and mineralocorticoids were observed to stimulate kidney Na-K-ATPase in similar sites and with similar time courses, this study was initiated to evaluate whether aldosterone is involved in the stimulation of Na-K-ATPase observed in collecting tubules $3 \mathrm{~h}$ after triiodothyronine $\left(T_{3}\right)$ administration to thyroidectomized (TX) rabbits. Results indicate that: (a) Plasma aldosterone level decreased markedly in TX rabbits but was not restored $3 \mathrm{~h}$ after $\mathrm{T}_{3}$ injection; (b) Early stimulation of Na-K-ATPase by $\mathrm{T}_{3}$ was abolished when plasma aldosterone level was suppressed by adrenalectomy or when aldosterone effects were blocked by spironolactone; (c) Administration of aldosterone to $\mathrm{TX}$ rabbits mimicked the action of $\mathrm{T}_{\mathbf{3}}$; (d) Sensitivity of Na-K-ATPase to aldosterone markedly decreased after thyroidectomy. These results demonstrate an interaction between aldosterone and $\mathrm{T}_{3}$ in the control of $\mathrm{Na}-\mathrm{K}$ ATPase in the collecting tubule. Triiodothyronine enhances the sensitivity of Na-K-ATPase to aldosterone which, in turn, produces a stimulatory action despite the decreased plasma level observed during hypothyroidism.
\end{abstract}

\section{Introduction}

It has been reported recently that thyroid hormones control the activity of Na-K-ATPase in specific segments of the rabbit nephron by two mechanisms which differ by their time course. Thus, within $1 \mathrm{wk}$ thyroidectomy induces a marked decrease of the activity and number of catalytic sites of Na-K-ATPase in the proximal and collecting tubules exclusively (1). After administration of a physiologic dose of triiodothyronine to thyroidectomized rabbits, Na-K-ATPase was restored according to a biphasic pattern; an early increase was observed within $3 \mathrm{~h}$, whereas the complete restoration up to control level occurred after 12$24 \mathrm{~h} \mathrm{(2).} \mathrm{If} \mathrm{the} \mathrm{late} \mathrm{response,} \mathrm{observed} \mathrm{in} \mathrm{both} \mathrm{proximal} \mathrm{and}$ collecting tubules is likely to correspond to the general action of thyroid hormones on Na-K-ATPase of most tissues (3-6), the early response observed in the collecting tubule exclusively might result from another process. The present study was thus initiated to characterize the mechanism of the early action of triiodothyronine on kidney Na-K-ATPase.

\footnotetext{
Address reprint requests to Dr. Doucet.

Received for publication 13 June 1986 and in revised form 24 September 1986.
}

J. Clin. Invest.

(c) The American Society for Clinical Investigation, Inc.

0021-9738/87/02/0629/03 \$1.00

Volume 79, February 1987, 629-631
Based on the similarities in the sites and time course of actions of thyroid hormones and mineralocorticoids on renal Na-KATPase, we searched for a possible role of aldosterone in the early stimulation by triiodothyronine of kidney Na-K-ATPase in the collecting tubule. Although the early response to thyroid hormones was observed in both cortical and outer medullary collecting tubules (2), the present study was restricted to the cortical portion, as it is much easier to microdissect than the medullary portion in the rabbit kidney.

\section{Methods}

Experimental protocol. Experiments were carried out on male New Zealand rabbits weighing 900-1,500 g and fed the usual laboratory diet ad lib. Adrenalectomy and/or thyroidectomy were performed under light pentobarbital anesthesia ( $35 \mathrm{mg} / \mathrm{kg}$ body wt, i.v.). After adrenalectomy, animals received a $0.9 \% \mathrm{NaCl}$ solution to drink.

5-8 d after surgery, adrenalectomized (ADX), thyroidectomized (TX) or thyroadrenalectomized rabbits (ADX+TX) were subcutaneously injected with different doses of aldosterone, triiodothyronine $\left(T_{3}\right)$, spironolactone, or any combination of these drugs, and they were sacrificed 3 $\mathrm{h}$ later.

Adequacy of thyroidectomy and adrenalectomy was assessed by the markedly decreased level of $T_{3}$ in the plasma of TX and ADX+TX animals and of aldosterone in the plasma of ADX and ADX + TX animals (Table I).

$N a-K$-ATPase measurement. Individual segments $(0.2-1.5 \mathrm{~mm}$ in length) of cortical collecting tubule (CCT) were microdissected from collagenase-treated kidneys using the technique previously described (7).

ATPase activity was determined on isolated CCT by the previously described radiochemical microassay after permeabilization of cell membranes (8). Na-K-ATPase activity was taken as the difference between the mean activity of total ATPase (determined in the presence of sodium and potassium) and the mean Mg-ATPase activity (determined in the absence of sodium and potassium and in the presence of ouabain), each being measured on four to five replicates.

Statistics. Statistical comparison of the various groups of animals was performed by variance analysis according to the test of Dunnett (9), $P$ values $<0.05$ being considered significant.

\section{Results}

Plasma aldosterone level. As shown in Table I, thyroidectomy induced a 55\% decrease of plasma aldosterone level within 8$12 \mathrm{~d}$. This decrease was not reversed $3 \mathrm{~h}$ after a single intravenous injection of $50 \mu \mathrm{g} / \mathrm{kg}$ body wt $\mathrm{T}_{3}$ (TX: $104 \pm 9 \mathrm{pg} \cdot \mathrm{ml}^{-1} \pm \mathrm{SE}, n$ $\left.=10 ; \mathrm{TX}+\mathrm{T}_{3}: 120 \pm 11 \mathrm{pg} \cdot \mathrm{ml}^{-1} \pm \mathrm{SE}, n=7 ; \mathrm{NS}\right)$.

Effects of hormone suppression and substitution on ATPase activity. Results depicted in Fig. 1 show that:

1. Abbreviations used in this paper: $\mathrm{ADX}$, adrenalectomized; CCT, cortical collecting tubule; $\mathrm{TX}$, thyroidectomized; $\mathrm{T}_{3}$, triiodothyronine. 
Table I. Aldosterone and $T_{3}$ Level in the Plasma of Control, TX, ADX, and ADX+TX Rabbits

\begin{tabular}{lll}
\hline & Aldosterone & $\mathrm{T}_{3}$ \\
\hline Control & $0.63 \pm 0.07(9)$ & $1.41 \pm 0.07(9)$ \\
TX & $0.28 \pm 0.02(10)^{*}$ & $0.04 \pm 0.13(16)^{*}$ \\
ADX & $0.02 \pm 0.01(6)^{*}$ & $0.80 \pm 0.10(8)^{*}$ \\
ADX+TX & $0.02 \pm 0.02(4)^{*}$ & $0 \pm 0(4)^{*}$
\end{tabular}

Aldosterone and $\mathrm{T}_{3}$ plasma levels (in $\mathrm{nM}$ ) were determined by radioimmunoassays (SB-Aldo H RIA kit, CEA, Saclay, France, and $T_{3}$ RIA kit, Amersham) on control animals or 5-8 d after surgery. Values are means $\pm \mathrm{SE}$, number of animals is given in parentheses.

* Statistically different from control at $P<0.001$ level.

(a) As previously described $(1,10)$ thyroidectomy as well as adrenalectomy markedly reduced Na-K-ATPase activity (by 7075\%) in the rabbit CCT.

(b) The decrease in Na-K-ATPase activity observed in the CCT of TX rabbits was partially restored (up to 60\%) $3 \mathrm{~h}$ after a single injection of $\mathrm{T}_{3}(50 \mu \mathrm{g} / \mathrm{kg}$ body $\mathrm{wt})$, as expected for the early response to $T_{3}(2)$.

(c) This stimulatory effect of $\mathrm{T}_{3}$ was completely abolished either when the antimineralocorticoid spironolactone was administered $(100 \mu \mathrm{g} / \mathrm{kg}$ body $\mathrm{wt}) \quad 30 \mathrm{~min}$ before $\mathrm{T}_{3}$ $\left(\mathrm{TX}+\right.$ spiro $\left.+\mathrm{T}_{3}\right)$, or when animals were adrenalectomized $\left(\mathrm{ADX}+\mathrm{TX}+\mathrm{T}_{3}\right)$.

(d) Finally, aldosterone mimicked the effect of $\mathrm{T}_{3}$ on $\mathrm{Na}$ K-ATPase activity in the CCT since administration of $10 \mu \mathrm{g} / \mathrm{kg}$ body wt aldosterone to TX rabbits $3 \mathrm{~h}$ before sacrifice restored the enzyme activity to the same level as $T_{3}$ administration did.

The above described changes in ATPase activity observed after thyroidectomy, adrenalectomy or hormone replacement were confined to its ouabain-sensitive moiety, as Mg-ATPase activity was not altered (Table II).

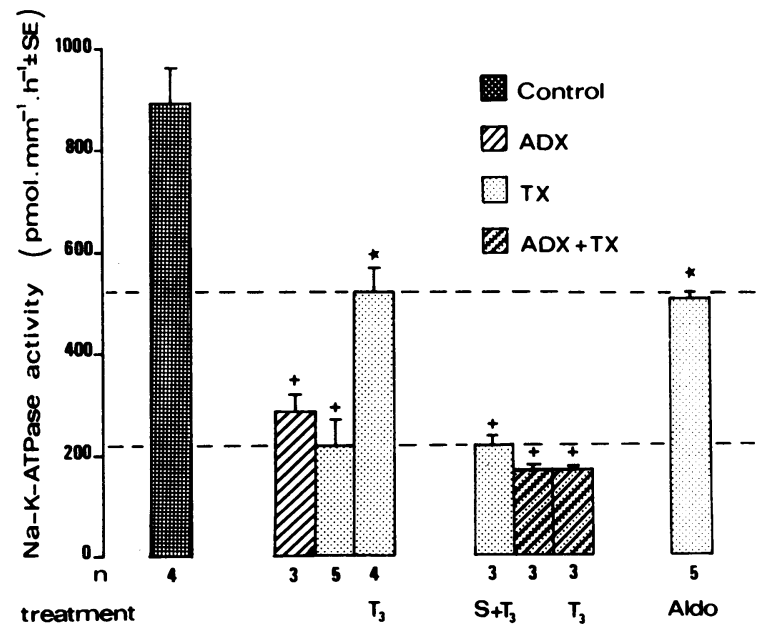

Figure 1. Na-K-ATPase activity was determined in the cortical collecting tubule of rabbits treated as follows: $\mathrm{C}$, normal; TX, thyroidectomized since 5-8 d; ADX, adrenalectomized since 5-8 d; ADX +TX, thyroidadrenalectomized since 5-8 d; $+\mathrm{T}_{3}, 3 \mathrm{~h}$ after administration of triiodothyronine ( $50 \mu \mathrm{g} / \mathrm{kg}$ body wt, s.c.); $+\mathrm{S}+\mathrm{T}_{3}$, administration of spironolactone ( $100 \mu \mathrm{g} / \mathrm{kg}$ body wt, s.c.) $30 \mathrm{~min}$ before $\mathrm{T}_{3} ;+$ aldo $3 \mathrm{~h}$ after administration of aldosterone ( $10 \mu \mathrm{g} / \mathrm{kg}$ body wt, s.c.). $n$, number of animals. All values are statistically different $(P$ $<0.001$ ) from controls; ${ }^{*} P<0.001$ as compared with TX animals; ${ }^{\dagger} P$ $<0.001$ as compared with $\mathrm{TX}+\mathrm{T}_{3}$.
Table II. Mg-ATPase Activity in the CCT of the Different Groups of Animals

\begin{tabular}{lc}
\hline Group & Mg-ATPase \\
\hline Control & $1,344 \pm 108(4)$ \\
TX & $1,141 \pm 75 \quad(5)$ \\
ADX & $1,069 \pm 80(3)$ \\
ADX+TX & $1,265 \pm 225(3)$ \\
TX+T & $1,111 \pm 11(4)$ \\
TX+Aldo & $1,416 \pm 120(5)$ \\
TX+T & $919 \pm 60(3)$ \\
ADX + TX $+T_{3}$ & $1,082 \pm 107(3)$ \\
\hline
\end{tabular}

Mg-ATPase activity of the different groups of animals (as depicted in the legend of Fig. 1) are expressed as pmol $\cdot \mathrm{mm}^{-1} \cdot \mathrm{h}^{-1} \pm \mathrm{SE}$, number of animals is indicated in parentheses. Values in the different groups are not statistically different.

Effect of thyroidectomy on the sensitivity of Na-K-ATPase to aldosterone. The dose dependence of $\mathrm{Na}-\mathrm{K}-\mathrm{ATPase}$ stimulation by aldosterone was compared between the CCT of adrenalectomized and thyroadrenalectomized rabbits. Results in Fig. 2 indicate that within $3 \mathrm{~h}$, a single dose of $2 \mu \mathrm{g} / \mathrm{kg}$ body wt aldosterone was sufficient to restore almost completely Na-K-ATPase activity in the CCT from ADX rabbits, whereas a dose fivefold higher was necessary to observe the maximal stimulation in the CCT from ADX+TX rabbits within the same delay.

\section{Discussion}

This study was aimed at evaluating whether aldosterone is implicated in the early stimulation of Na-K-ATPase previously described in the CCT in response to the administration of $T_{3}$ to thyroidectomized rabbits (2). It was initiated on the basis of the following observations: (a) Mineralocorticoids and thyroid hormones share similar intracellular mechanisms of action which consist in controlling expression of specific genes (11-14); (b) These hormones control the activity and the number of catalytic sites of Na-K-ATPase at the same sites in the kidney, the col-

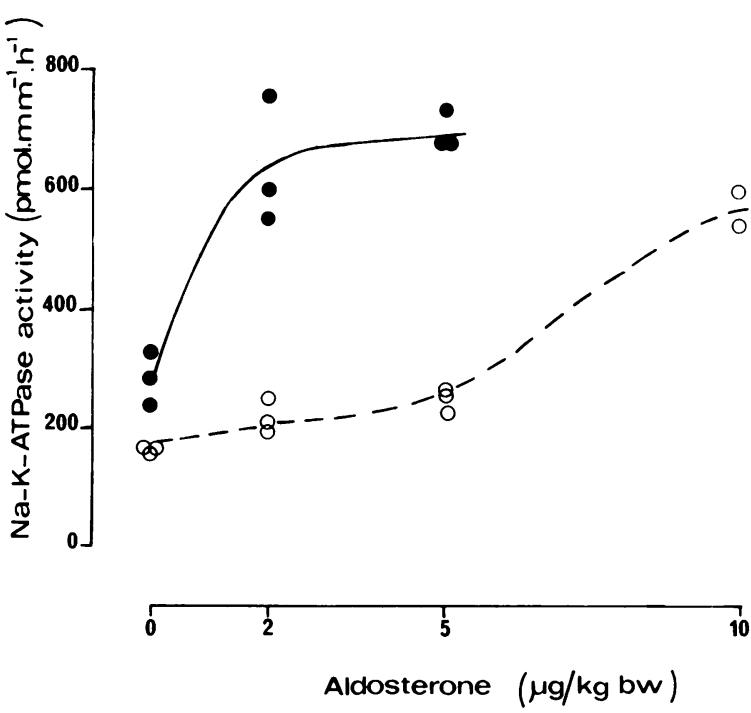

Figure 2. Na-K-ATPase activity in the CCT of adrenalectomized (solid circle) or thyroadrenalectomized rats (open circle) $3 \mathrm{~h}$ after subcutaneous injection of doses of aldosterone between 2 and $10 \mu \mathrm{g} / \mathrm{kg}$ body wt (bw). Each point is the result of an individual experiment. 
lecting tubule $(1,15) ;(c)$ They produce this control with similar kinetics $(2,16)$ and, $(d)$ Finally, aldosterone secretion rate (17) and plasma level (18) are decreased in hypothyroid animals.

Present results clearly demonstrate that the presence of aldosterone is required for the early stimulation of Na-K-ATPase by $\mathrm{T}_{3}$ since, on the one hand, removal of circulating aldosterone by adrenalectomy or blocking aldosterone effect by spironolactone abolished this action (Fig. 1) and, on the other hand, administration of large doses of aldosterone to TX rabbits mimicked the action of $\mathrm{T}_{3}$ (Fig. 1).

However, although plasma aldosterone level decreased 1 wk after thyroidectomy (Table I), it did not increase within $3 \mathrm{~h}$ after $\mathrm{T}_{3}$ administration, i.e., when the aldosterone-mediated early stimulation of Na-K-ATPase was completed. This observation demonstrates that within this delay $\mathrm{T}_{3}$ does not increase aldosterone secretion and suggests that thyroid hormones enhanced the sensitivity of the collecting tubule to aldosterone. This later hypothesis was confirmed by the finding that the sensitivity of Na-K-ATPase to aldosterone observed in the CCT of adrenalectomized rabbits decreased fivefold when animals were thyroidectomized in addition (Fig. 2). This is in agreement with a report by Taylor and Fregly showing that the antinatriuretic response to mineralocorticoid required to be observed doses of hormone 10-fold higher in hypothyroid than in euthyroid rats (19). This similarity of dependence of aldosterone action towards thyroid hormones on both Na-K-ATPase activity of the CCT and sodium reabsorption by the kidney is another evidence, in addition to the previously described kinetical similarities of these two actions previously (16), demonstrating that induction of tubular Na-K-ATPase is one of the primary events mediating the antinatriuretic action of aldosterone on the kidney.

Interactions between thyroid hormones and aldosterone were also observed in amphibian urinary bladder by Rossier and colleagues who reported that $T_{3}$ inhibited aldosterone-stimulated rate of sodium transport (20). This antagonism occurs through the occupancy of specific nuclear receptors to $T_{3}(21)$ and, in the absence of alterations of the rate of synthesis of Na-K-ATPase (22), is probably brought about via induction and/or repression of proteins which, in turn, interfere with the physiological action of aldosterone (23). Although the interaction between $T_{3}$ and aldosterone described in amphibians is different from that depicted in the present paper, which may reflect differences between poikilotherms and homeotherms, its molecular basis might be similar in mammalians and amphibians.

In summary, the present study demonstrates that aldosterone is responsible for the early stimulation of Na-K-ATPase by $\mathrm{T}_{3}$ in the collecting tubule: $T_{3}$ enhances the sensitivity of target cells to aldosterone allowing this later to produce its usual stimulatory action despite its decreased level in the plasma of hypothyroid animals. The molecular basis of this facilitating action of $T_{3}$ has not been elucidated yet.

\section{Acknowledgments}

Authors are grateful to Mrs. V. Biausque and S. Siaume-Perez for helping in the preparation of the manuscript.

This work was supported in part by a grant from the Centre National de la Recherche Scientifique.

\section{References}

1. Barlet, C., M. Ben Abdelkhalek, and A. Doucet. 1985. Sites of thyroid hormone action on Na-K-ATPase along the rabbit nephron. Pfluegers Arch. Eur. J. Physiol. 405:52-57.
2. Barlet, C., and A. Doucet. 1986. Kinetics of triiodothyronine action on Na-K-ATPase in single segments of rabbit nephron. Pfluegers Arch. Eur. J. Physiol. 407:27-32.

3. Edelman, I. S., and F. Ismail-Beigi. 1974. Thyroid thermogenesis and active sodium transport. Recent Prog. Horm. Res. 30:235-257.

4. Haber, R. S., and J. N. Loeb. 1984. Early enhancement of passive potassium efflux from rat liver by thyroid hormone: relation to induction of Na-K-ATPase. Endocrinology. 115:291-297.

5. Philipson, K. D., and I. S. Edelman. 1977. Thyroid hormone control of $\mathrm{Na}^{+}-\mathrm{K}^{+}$-ATPase and $\mathrm{K}^{+}$-dependent phosphatase in rat heart. $\mathrm{Am}$. J. Physiol. 232:C196-C201.

6. Philipson, K. D., and I. S. Edelman. 1977. Characteristics of thyroid-stimulated $\mathrm{Na}^{+}-\mathrm{K}^{+}$-ATPase of rat heart. Am. J. Physiol. 232:C202C206.

7. Morel, F., D. Chabardès, and M. Imbert-Teboul. 1978. Methodology for enzymatic studies of isolated nephron segments. In Methods of Pharmacology. M. Martinez-Maldonado, editor. Vol. 4B. Plenum Press, New York. 297-323.

8. Doucet, A., A. I. Katz, and F. Morel. 1979. Determination of NaK-ATPase activity in single segments of the mammalian nephron. $\mathrm{Am}$. J. Physiol. 237:F105-F113.

9. Dunnett, C. W. 1955. A multiple procedure for comparing several treatments with a control. J. Am. Stat. Assoc. 50:1096-1121.

10. El Mernissi, G., and A. Doucet. 1983. Short-term effects of aldosterone and dexamethasone on Na-K-ATPase along the rabbit nephron. Pfluegers Arch. Eur. J. Physiol. 399:147-151.

11. Edelman, I. S., R. Bogoroch, and G. A. Porter. 1963. On the mechanism of action of aldosterone on sodium transport: the role of protein synthesis. Proc. Natl. Acad. Sci. USA. 50:1169-1177.

12. Oppenheimer, J. H. 1979. Thyroid hormone action at the cellular level. Science (Wash. DC). 203:971-979.

13. Oppenheimer, J. H., D. Koerner, H. L. Schwartz, and M. I. Surks. 1972. Specific nuclear triiodothyronine binding sites in rat liver and kidney. J. Clin. Endocrinol. Metab. 35:330-333.

14. Porter, G. A., R. Bogoroch, and I. S. Edelman. 1964. On the mechanism of action of aldosterone on sodium transport: the role of RNA synthesis. Proc. Natl. Acad. Sci. USA. 52:1326-1333.

15. El Mernissi, G., and A. Doucet. 1984. Specific activity of Na-KATPase after adrenalectomy and hormone replacement along the rabbit nephron. Pfluegers Arch. Eur. J. Physiol. 402:258-263.

16. El Mernissi, G., and A. Doucet. 1983. Short-term effect of aldosterone on renal sodium transport and tubular Na-K-ATPase in the rat. Pfluegers Arch. Eur. Biochem. 399:139-146.

17. Fregly, M. J., J. R. Cade, I. W. Waters, J. A. Straw, and R. E. Taylor Jr. 1965. Secretion of aldosterone by adrenal glands of propylthiouracil-treated rats. Endocrinology. 77:777-784.

18. Montiel, M., E. Jimenez, J. A. Narvaez, M. Ruiz, and M. Morell. 1984. Effects of two different experimental situations of hypothyroidism on serum aldosterone concentration and plasma renin in rats. Rev. Esp. Fisiol. 40:431-436.

19. Taylor, R. E., Jr., and M. J. Fregly. 1964. Renal response of propylthiouracil-treated rats to injected mineralocorticoids. Endocrinology. 75:33-41.

20. Rossier, B. C., H. P. Gäggeler, D. B. Brunner, I. Keller, and M. Rossier. 1979. Thyroid hormone-aldosterone interaction on $\mathrm{Na}^{+}$transport in toad bladder. Am. J. Physiol. 236:C125-C131.

21. Geering, K., and B. C. Rossier. 1981. Thyroid hormone-aldosterone antagonism of $\mathrm{Na}^{+}$transport in toad bladder. J. Biol. Chem. 256: $5504-5510$.

22. Geering, K., M. Girardet, C. Bron, J. B. Kraehenbühl, and B. Rossier. 1982. Hormonal regulation of $\left(\mathrm{Na}^{+}, \mathrm{K}^{+}\right)-\mathrm{ATPase}$ biosynthesis in the toad bladder. Effect of aldosterone and 3,5,3'-triiodo-L-thyronine. J. Biol. Chem. 257:10338-10343.

23. Truscello, A., H. P. Gäggeler, and B. C. Rossier. 1986. Thyroid hormone antagonizes an aldosterone-induced protein: a candidate mediator for the late mineralocorticoid response. J. Membr. Biol. 89:173183. 